\title{
Supporting the design and development of Project Based Learning courses
}

\author{
Javier García Martín, Carlos López López, Jorge E. Pérez Martínez \\ E.T.S. Ingeniería de Sistemas Informáticos \\ Universidad Politécnica de Madrid \\ Madrid, Spain \\ jgarcia@eui.upm.es
}

\begin{abstract}
The use of Project Based Learning has spread widely over the last decades, not only throughout countries but also among disciplines. One of the most significant characteristics of this methodology is the use of ill-structured problems as central activity during the course, which represents an important difficulty for both teachers and students. This work presents a model, supported by a tool, focused on helping teachers and students in Project Based Learning, overcoming these difficulties. Firstly, teachers are guided in designing the project following the main principles of this methodology. Once the project has been specified at the desired level of depth, the same tool helps students to finish the project specification and organize the implementation. Collaborative work among different users is allowed in both phases. This tool has been satisfactorily tested designing two real projects used in Computer Engineering and Software Engineering degrees.
\end{abstract}

Keywords-Problem Based Learning; Project Based Learning; Ill-Structured; Computer Support; ICT

\section{INTRODUCTION}

Project and Problem Based Learning (PBL) is a teachinglearning method that has been used in North America and Northern Europe since the early 1970s. It has shown many benefits in different branches of knowledge, such as Health, Engineering and Social Sciences. In recent decades PBL has spread to other areas, like Southern Europe, Asia or South America, getting a good acceptance. In this context, Kolmos [1] highlights the growing diversity in the implementation of PBL and defends aiming for diversity within a framework of community building, although the development of guidelines for institutional self-assessment would be recommended in order to follow the learning principles.

\section{A. PBL principles}

Therefore, it is important to follow these learning principles in order to obtain a real benefit from PBL learning strategy. Kolmos [2] and other works summarize the principles of PBL formulated by Barrows [3]: the use of problems as a startingpoint for the acquisition and integration of new knowledge, new information acquired through self-directed learning, student-centered, learning in small groups, and teachers acting as facilitators and guides rather than informants.
De Graff [4] summarizes the typical learning principles described by different authors who established the theoretical roots of PBL, adding some new items to the previous list:

- Activity-based learning, requiring activities involving research, decision-making and writing.

- Inter-disciplinary learning, extending beyond traditional subject-related boundaries and methods.

- Exemplary practice, ensuring that the benefits for the students are exemplary in terms of the objectives.

The selection of a good problem is critical for the success of the course. Subsequently, another important issue is the set of characteristics that should be fulfilled by a problem in PBL strategy. In this regard [5] lists the following requirements:

- It is engaging and oriented to the real-world.

- It is ill-structured and complex.

- It generates multiple hypotheses.

- It requires team effort.

- It is consistent with desired learning outcomes.

- It builds upon previous knowledge/experiences.

- It promotes development of higher order cognitive skills.

Reference [6] points out that one important difference between "discipline and teacher-controlled courses" and "innovative and learner-centered courses" is the type of problems or projects that are presented to students. While wellstructured problems are characteristic for the former, learnercentered courses require ill-structured problems.

Let us discuss in more detail this last issue, ill-structured problems, since we consider it is one of the cornerstones of PBL and one of the main sources of difficulties in using PBL. The main differences between well- and ill-structured problems are described in [7] and [8]. Well-structured problems consist of a well-defined initial state, a known goal state, and a constrained set of logical operations. They present all elements of the problem and are presented to learners as well-defined problems with a probable solution. They engage the application of a limited number of rules and principles with constrained 
parameters that lead to correct and converging answers. On the other hand, Jonassen [7] defines ill-structured problems in the next way: "Ill-structured problems are typically situated in and emergent from specific context. In situated problems, one or more aspects of the problem situation are not well specified, the problem descriptions are not clear or well defined, or the information needed to solve them is not constrained in the problem statement". Therefore, in this kind of problems one or more of the problem elements are unknown or not known with any degree of confidence, goals are vague or unclear, there are multiple solutions and solution paths (or even no consensual solution), they present uncertainly about which concepts, rules and principles are necessary, learners are required to express personal opinion, beliefs or judgments. Besides explaining these differences, Jonassen describes the different processes that are needed to design Well- and Ill-Structured Problem Solving Instruction, as well as the different processes needed for solving Well- and Ill-Structured problems.

\section{B. Difficulties to implement $P B L$}

Students are required to develop different processes and skills depending on the kind of problem they are tackling [8] [9]. Solving Ill-Structured processes include (a) recognizing that there is a problem, (b) finding out exactly what the problem is, (c) searching and selecting some information about it, (d) developing justification by identifying alternative perspectives, (e) organizing obtained information to fit a new problem situation, (f) generating some possible solutions, (g) deciding on the best solution by the solver's perception of problem constraints, and (h) implementing the solution and evaluating it by developing arguments and articulating personal belief or value.

As far as skills are concerned, for both kinds of problems structural knowledge and domain-specific knowledge are required. However, metacognition (such as searching, planning etc.), ability to develop justification, and non-cognitive variables (such as attitude, motivation etc.) are more specific to solve ill-structured problems.

As Jonassen [10] asserts "We cannot assume that learners are naturally skilled in problem solving, especially complex and ill-structured problems such as those required in most PBL programs". From our point of view, and based on our experience, this issue is related to some of the most important problems in PBL implementation. In some academic contexts, students are not used to dealing with this kind of problems, therefore they feel lost and end up rejecting the methodology.

Regarding teachers' difficulties, Sumg Hee [11] presents a study focused on the barriers that middle school teachers face when they are implementing technology-enhanced problembased learning (PBL) in their classrooms. The study is based on interviews to different academic personnel. Results suggest that lack of a clear, shared vision was the primary barrier. Other difficulties are related to the new teachers' role, where they have to change from a knowledge transmitter to a guide or facilitator, losing control on the student work. Besides, some teachers find difficulties in designing PBL activities that fulfill the main characteristics of this methodology. Consequently, these difficulties make some organizations to give up or reject PBL.

\section{Needs and goals}

For the abovementioned reasons, we perceive the need to introduce PBL in academic contexts overcoming these barriers, so that PBL is accepted by teachers and students and they make the most of it. This paper proposes a model, based on some previous works [12] to help both teachers and students to design and develop the project that is used as scaffold during a PBL course. This model is supported by a computer tool (PBLT) that has been implemented at the Computer Science School (Universidad Politecnica de Madrid) [13]. Teachers are guided on how to design a project-centered course taking into account the main principles of PBL methodology, whilst student groups are guided on how to develop their own implementation of this project, including issues such as organization, planning or resource management. Its most significant features are:

- to integrate the activities of both teachers (design) and students (develop) in the same tool.

- to offer a collaborative environment for both, teachers' team and students' team.

- to allow different levels of depth in the project specification, in such a way that teachers can design a project at the desired level between well- and illstructured.

- to take into account specific issues of academic contexts, like courses or lessons.

- to allow remote work.

\section{Previous works}

Reference [14] describes six types of technological tools to support PBL, according to who is going to receive this support: a) teachers; b) students; c) contents, and according to the interrelation between: d) teachers and contents; e) teachers and students, and f) students and contents. Many studies are focused on supporting student activities and contents. With this perspective, [15] classifies resources according to the educational functions and activities for which they will be used. Besides, it discusses communication patterns, assessment and evaluation. Reference [16] analyses the communication tools that are used by students in a distributed problem based learning environment. In the same context, some Learning Management Systems, like the platform Moodle, are used to support the contents and activities of PBL courses.

On the other hand, studies that deal with supporting teachers' work are mainly focused on providing guides or instructional resources, such as rubrics, project planners, project examples, etc. [17]. In this work we propose a tool that not only provides online support for teachers to design PBL courses, but also links their work with the subsequent students' work to implement the project.

\section{E. Paper structure}

Section II describes the model proposed to design and develop a project, together with the tool implemented. It starts with a general vision and then explains the different phases to design and put into practice a PBL course. Section III presents the main results obtained from two general tests based on real 
academic projects. Finally, conclusions and future works are presented in section IV.

\section{MODEL AND TOOL DESIGN}

\section{A. The big picture}

First of all, the tool distinguishes between two phases: project design and project implementation. During the design phase, teachers elaborate the project that will be used as central problem for the PBL course. Once the project has been designed, PBLT allows teachers to create multiple instances of the same project. Each instance is assigned to a different student team. Then the second phase starts, in which every student team develops its own project implementation (Fig.1).

During the design phase, the tool guides teachers to elaborate the project following some important principles of PBL methodology: the use of problems as a starting-point and the role of teachers as facilitators and guides rather than informants. Different users can develop collaborative remote work, so that several instructors can work together to elaborate the same project. Before creating multiple instances of the project, instructors decide which aspects of the project can be modified by students during the project implementation. In this regard, instructors determine the state of every issue included in the specification: open or closed, so that students can modify afterwards those aspects that are not closed.

There is no clear frontier between well-structured and illstructured problems. When designing a PBL course, instructor can develop a project specification more or less detailed. The level of detail will depend on several factors, among them: maturity of students, familiarity with this kind of problems, teachers' expertise and academic context such as assessment rules. The point is that both teachers and students feel confident and comfortable. In this regard, PBLT can cover a great number of data related to the project specification, from a general description to a detailed specification of the phases that constitute the project. Nevertheless, the instructors decide the information that will be included.

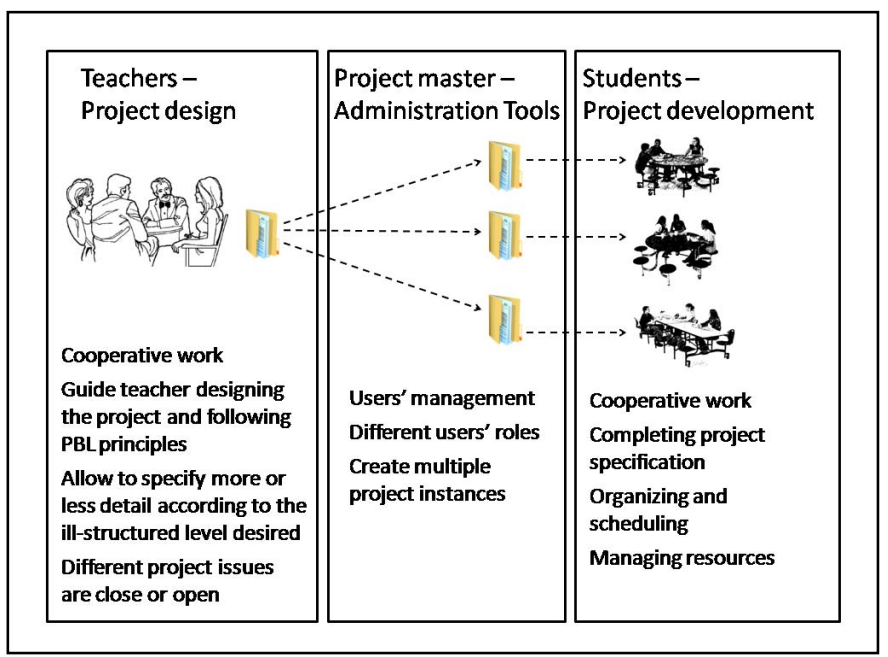

Fig. 1. General vision
Although a complete description of this phase will be given in next section, to illustrate this point, instructors can specify a general description of the project (project objective, context, restrictions), provide an incomplete set of references, supply some tools, establish some important events (for instance milestones or hand-ins) and include a brief description of the first project phases. The general description of the project could be closed, so that student will not be able to modify afterwards, whilst references and project phases are open. In this way, student teams could complete these aspects.

During the implementation phase, student groups develop their own project implementation. The students' work consists of two kinds of activities. Firstly, they must conclude the project specification, starting from the point established in the instructors' specification. Thus they will complete all the information that is needed to develop the project but it is not provided by the instructors. Moreover, they can modify the open aspects mentioned above. Secondly, they proceed to implement the project. In this regard, the support of PBLT is focused on the project organization. Students detail aspects such as the tasks that they are going to carry out during every project phase, meetings or sources of information that are useful to implement the project. In addition, the tool presents a chronogram for every phase to make easier its scheduling. The chronogram displays the tasks and events.

Continuing with the previous example, students cannot add information to the general description, for instance modify the context or include new objectives. However, they can complete the list of tools and the phases needed to complete the project. In addition, students must detail information such as important events, meetings and the set of tasks that should be executed to carry out every phase.

\section{B. Designing the project}

The model proposes to divide the information that makes up the project specification into three areas, according to its aim: definition, support and organization. The definition area is focused on providing students the information to know what they have to do. First, it includes a general description of the project consisting of the name, context, definition and the main goal of the project. Next, specific goals, restrictions and beginning and end dates are defined.

Support information supplies student a scaffold to help them to develop the project. It incorporates a description of the courses that are related to the project and can support its development. A course description can consist of a brief enumeration of the learning outcomes and topics covered by the course. On the contrary, instructors can opt for adding more elaborate information including lessons, modules of every lesson, lab tasks, lab sessions and a calendar of these activities. Moreover, supporting references (web sites or pdf files), useful tools and a description of the methodologies used in sessions are included.

Finally, information to organize the project is provided by specifying the phases necessary to carry out the project and establishing important events such as meetings or hand-ins. Each phase specification can include a great amount of information associated to this phase, although instructors can 
decide the level of detail as we explain in the previous section. This information consists of a description, the main difficulties that could be found, its specific goals, useful tools, course sessions (lessons or lab tasks) associated to this phase, meetings and helpful references.

All aspects that have a date associated, like beginning and end dates, sessions, events or meetings are automatically registered in a calendar. In this way, users can monitor the project scheduling at any time. Fig. 2 shows a schema for this information items.

Fig. 3 displays the main window of PBLT. Besides a top menu that provides access to general functions, such as opening and closing projects, generating reports or master activities, the main page consists of three areas. The area located at the top left of the window shows the name of the project that is open along with its phases. These phases are also shown by a graph on the right side, including the order of precedence. On the lower left side, the third area shows the calendar project generated automatically with the data included during the project specification.

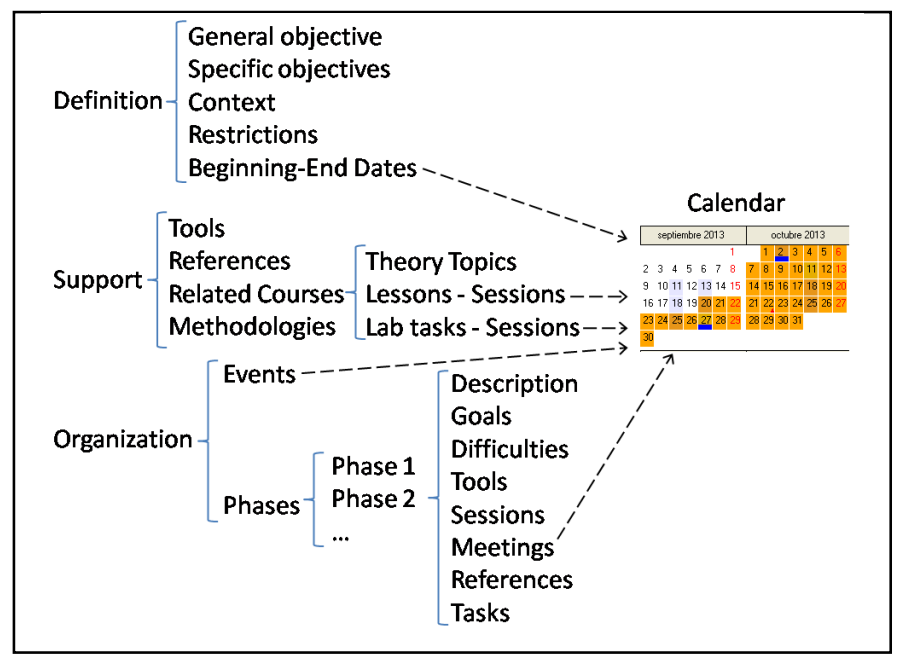

Fig. 2. Organization of project information

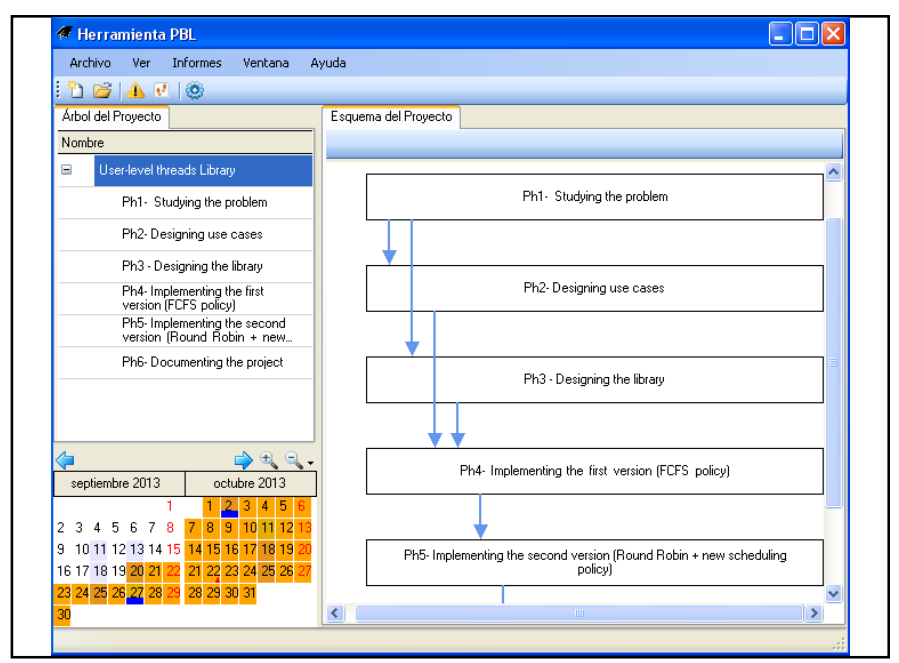

Fig. 3. Main window
By clicking on the project name, users can access a new menu that allows basically three operations: access the project properties window, create and delete phases within the project and generate a new instance of the project.

The project properties window (Fig. 4) is used to introduce the information abovementioned related to the project description and support. Similarly, by clicking on a phase in the graph we can access the phase window. This window allows users to define all the information previously explained and related to this phase.

Just to illustrate a new functionality of PBLT, Fig. 5 shows the window in which the user is including an event within the project. In this case, besides writing the event name and description, the user specifies the date of this event throughout a calendar. This date is automatically translated to the general project calendar included in the main window.

\section{Preparing the implementation}

Once the project has been specified at the desired level of detail, instructors leave open those items that student will be able to modify. On the contrary, other issues will be closed for

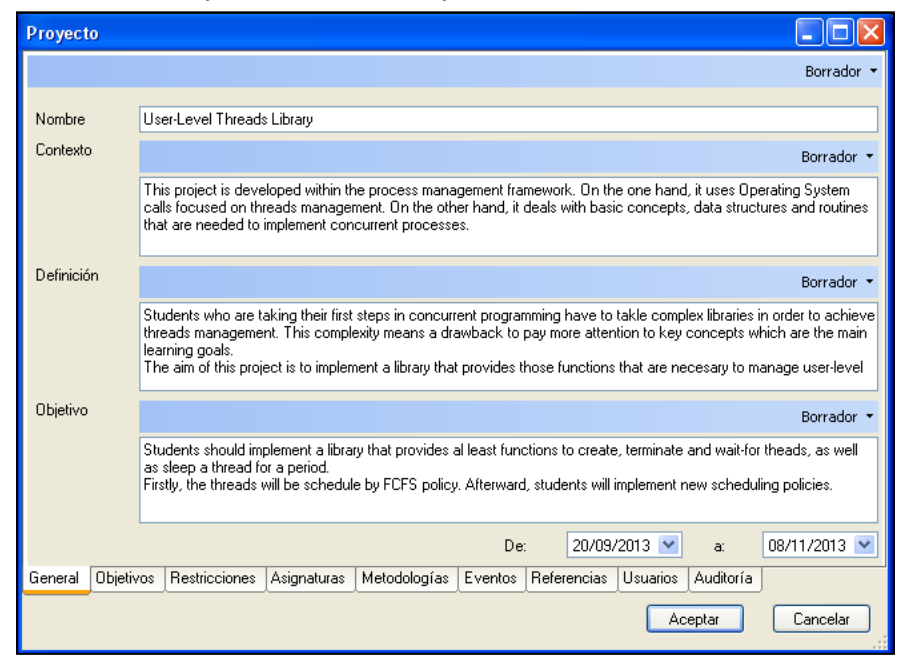

Fig. 4. Editing project definition

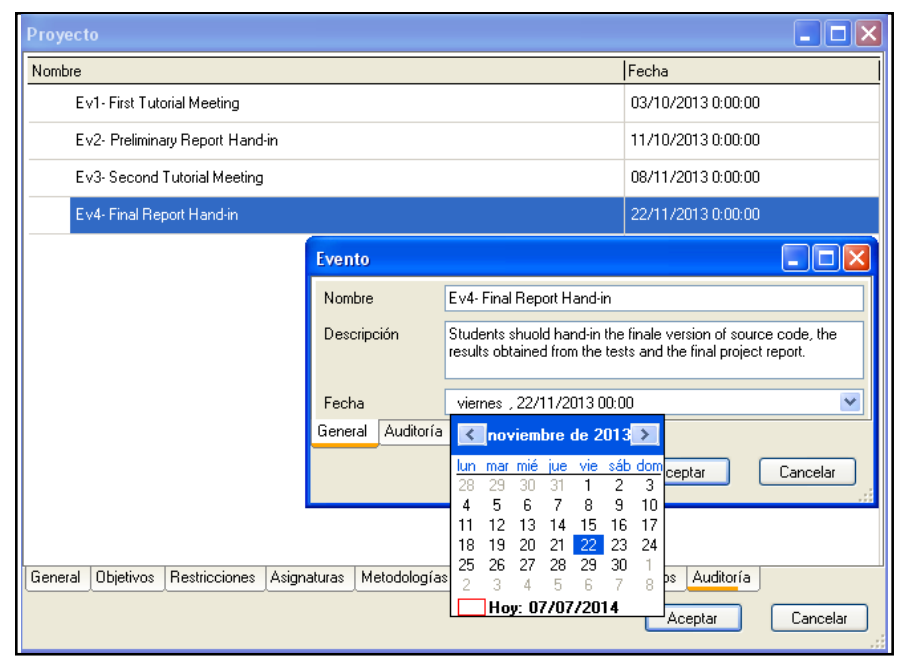

Fig. 5. Specification of an event 
future changes. The next task consists in registering the users (students) who will participate in the project development. Moreover, student groups are configured. Finally, a new project instance is created for every student group and assigned to it.

\section{Project development}

Throughout the last part of the process, each student group develops its own implementation. Their first view is the one provided by instructors. They have access to the same menus and options. In this way they can complete those issues that were left open or were not specified by instructors.

Nevertheless, student groups have access to a new menu placed above the phases graph area. This menu consists of a tab for every project phase and can be observed in Fig. 6. By clicking on a phase tab, PBLT replaces the phases graph by specific information for this phase. In particular, a list of the meetings and tasks associated to this phase are shown on the left, together with the important project events. The right side displays a chronogram that shows the months, weeks and days at the top. In addition, the graph depicts events, meetings and tasks. Besides consulting this information, students can perform several operations by clicking directly on the graph:

- Edit the information of an item and modify it

- Change the date of an item by dragging it over the graph
- Establish precedence relationship between items

\section{E. Tecnological issues}

The software framework .NET was used to implement PBLT. The Data Base was developed by using Microsoft SQL Server 2005.

Multi-tier architecture was chosen in order to support the collaborative environment. In this architecture there is an application server in charge of synchronizing every client application. These client applications implement the user interface.

Every access to the data repository is carried out through the application server. This server stores into a queue every data modification transaction that is made. In this way it can notify this modification to every client, which can update its local data models.

\section{RESULTS}

PBLT has been tested with two practical examples. Firstly, an example about operating system performance was used to test the general functionality. This project corresponds to a real project developed in the Operating Systems course (fifth semester of Computer Engineering degree) and consists in implementing new functionalities by using the operating system interface. This was the first general test and then was mainly used to detect failures, improve the user interface and add functionalities. This example covered both phases of the

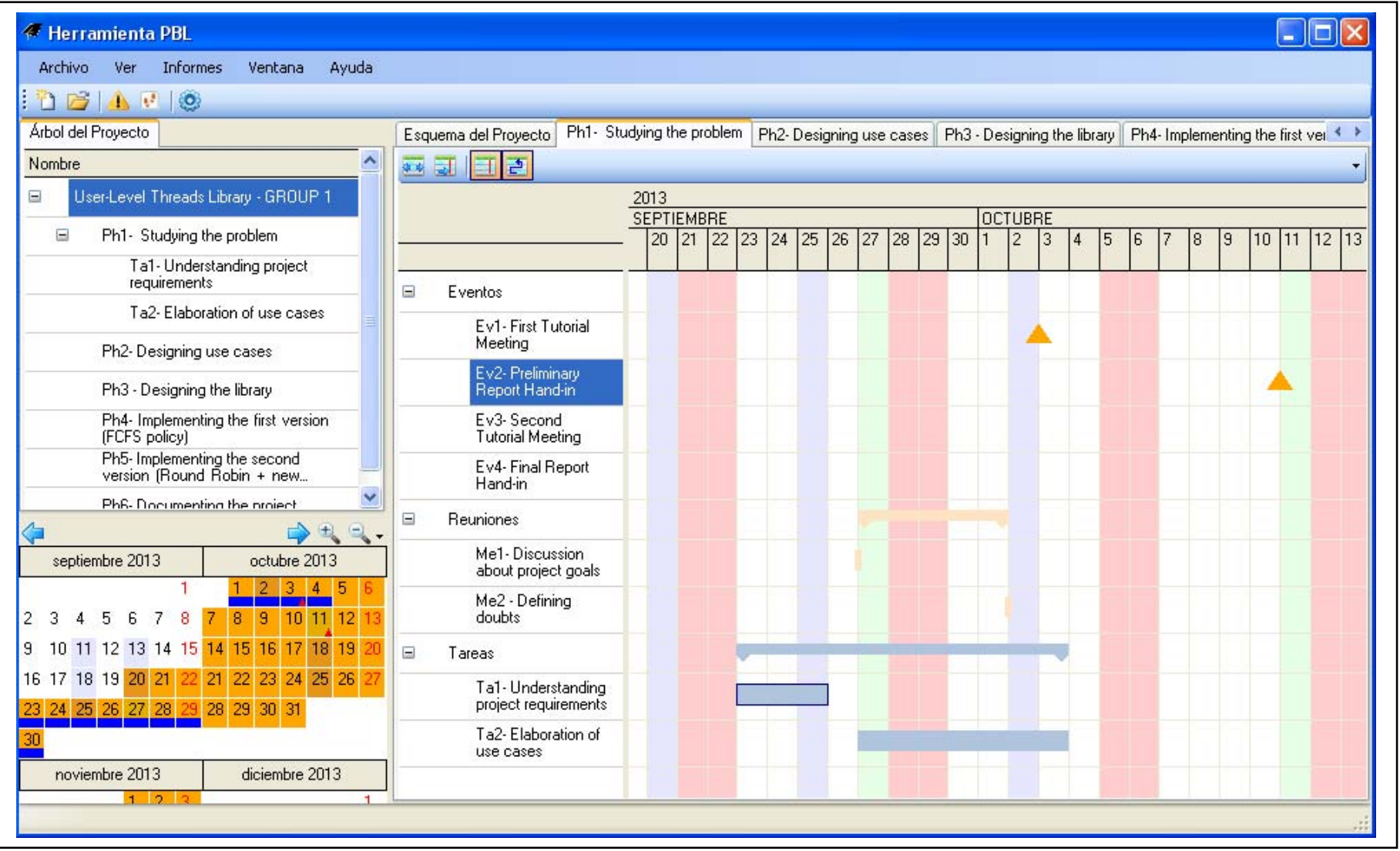

Fig. 6. Scheduling project development 
process: project design (developed by instructors) and project implementation (developed by students), although the second one was simulated with two virtual, not real, student groups.

This test served to detect some minor failures, improving the interface when the user was writing item descriptions and adding a new functionality, generating reports, that was not included in the initial requirements.

The second test consisted in a more sophisticated example and was used to develop a deeper check of the functionality and performance of PBLT, as well as its validation. The example is a real project that was put into practice in the third semester of the Software Engineering degree and involves three different compulsory courses: Operating Systems, Software Requirement Engineering and Statistics. In this case students have to specify, design and implement a new application to compare the performance of two operating systems. By using this application, students have to design an experiment and develop a statistical analysis of the results. Due to the complexity, instructors considered necessary to provide more information in the project design. For instance, more references, more information about the courses (lessons and laboratory sessions) and more information about the phases of the project. This test was carried out after including the modifications and improvements considered during the first test. In this case, the second part (student implementation) was not tested.

\section{CONCLUSIONS AND FUTURE WORKS}

In this work we have proposed a model to support the design and development of projects that are used in PBL courses. The model allows different levels of depth during the project specification. Moreover, we present a tool that supports this model. The tool satisfies the initial requirements and goals, besides having a handy interface.

According to the two tests described in the previous section, the model and tool seem to be useful to guide teachers to design PBL courses in which the problem is the central activity during the students learning. Both the method and the tool adapt satisfactorily to different kinds of problems, regarding the ill-structured characteristic.

Although PBLT is considered useful and convenient, we see that some training before using it is necessary, so that new users can become familiar with PBL concepts and the way in which they are represented in PBLT.

As future work, we will test the second part of the process, student development, in a real scenario where students organize their own project in a collaborative environment. These realistic scenarios will allow us to think on new functionalities. In particular, we will cover the assessment of student projects, issue that has not been considered in this first version. Moreover, we are currently working on translating this tool into English.

\section{ACKNOWLEDGMENT}

This work has been partially funded in the academic years 2010-2011 and 2011-2012 by the Universidad Politécnica de Madrid.

\section{REFERENCES}

[1] A. Kolmos, "Problem- and project- based learning in a global perspective: Community bulding or certification?", in Visions Challenges and Strategies. Aalborg University Press. Eds. Lone Krogh and Annie Aarup Jensen, 2013, pp.47-66.

[2] A. Kolmos, "Changing the Curriculum to Problem-Based and ProjectBased Learning" in Outcome-Based Science, Technology, Engineering, and Mathematics Education: Innovative Practices, Eds. Khairiyah Mohd Yusof; Naziha Ahmad Azli; Azlina Mohd Kosnin; Sharifah Kamilah Syed Yusof; Yudariah Mohammad Yusof. IGI global, 2012. p. 50-61.

[3] H.S. Barrows, "Problem-based Learning in Medicine and Beyond:A Brief Overview", in Bringing Problem-Based Learning to Higher Education: Theory and Practice. Eds. LuAnn Wilkerson and Wim H. Gijselaers. San Francisco: Joseey-Bass, New Directions for Teaching and Learning, 1996, 68:3-12.

[4] E. De Graaff, and A. Kolmos, "Characteristics of problem-based learning", International Journal of Engineering Education, 2003, vol. 19, no. 5, pp. 657-662.

[5] B.S. Bloom, Taxonomi of Educational Objectives. The Classification of Educational Goals. Handbook 1: Cognitive Domain. David Mckay Company, New York, 1956.

[6] A. Kolmos, E. de Graaff and X. Du, (2009). "Diversity of PBL-PBL learning principles and models", in Research on PBL practice in engineering education, Eds. X. Du, E. de Graaff, and A. Kolmos, Sense Publishers, 2009, pp. 1-7.

[7] D.H. Jonassen, "Instructional design models for well-structured and illstructured problem-solving learning outcomes" in ETR\&D, vol 45, No 1, 1997, pp 65-69.

[8] S.H. Namsoo, The relationship between well-structured and illstructured problem solving in multimedia simulation, The Pennsylvania State University, Thesis in Instructional Systems, 1998.

[9] J. F. Voss and T. A. Post, "On the solving of ill-structured problems", in The nature of expertise. Hillsdale, Eds. M. T. H.Chi, R. Glaser, and M. J. Farr, NJ:Lawrence Erlbaum, 1988.

[10] D. Jonassen, "Supporting Problem Solving in PBL. Interdisciplinary Journal of Problem-based Learning", vol. 5 no. 2, 2011. Available at: http://dx.doi.org/10.7771/1541-5015.1256

[11] Sung Hee Park and Peggy A. Ertmer, "Examining barriers in technology-enhanced problem-based learning: Using a performance support systems approach", in British Journal of Educational Technology, vol. 39 no. 4 pp. 631-643, 2008.

[12] J. Garcia and J.E. Perez, “A PBL Application Experience Supported by Different Educational Methodologies", in Research on PBL Practice in Engineering Education, Eds. Xiangyun Du, Erik de Graaff and Anette Kolmos, Rotterdam: Sense Publisher, 2009, pp. 139-153.

[13] C. López, Herramienta para el apoyo al diseño e implementación de un curso basado en la metodología PBL. Trabajo Fin de Carrera. E.T.S.I Sistremas Informáticos. 2014. In press.

[14] A. Badia and C. García, "Incorporación de las TIC en la enseñanza y el aprendizaje basados en la elaboración colaborativa de proyectos", in Enseñanza y aprendizaje con TIC en la educación superior [on line], Eds. Antoni Badia, Revista de Universidad y Sociedad del Conocimiento (RUSC), vol. 3, no. 2. UOC, 2006. [Fechade consulta: 24/04/14]. http://www.uoc.edu/rusc/3/2/dt/esp/badia_garcia.pdf, last access April $25,2014$.

[15] A. Ellis et all. "Resources, tools, and Techniques for Problem Based Learning in Computing", ITiCSE-WGR '98 Working Group reports of the 3rd annual SIGCSE/SIGCUE ITiCSE conference on Integrating technology into computer science education, pp. 41-56. ACM New York, NY, USA. 1998.

[16] C.S. Cheng and C. Beaumont, "Evaluating the effectiveness of ICT to support globally distributed PBL teams", ITiCSE '04 Proceedings of the 9th annual SIGCSE conference on Innovation and technology in computer science education, pp. 47-51. ACM New York, NY, USA, 2004.

[17] The Buck Institute for Education (BIE), http: \www.BIE.org, last access April 25, 2014. 